\title{
LA FUNCIÓN SOCIAL DEL PATRIMONIO ARQUEOLÓGICO LOCAL. LA PUESTA EN VALOR DE LA NECRÓPOLIS DE LA CALERILLA DE HORTUNAS DE REQUENA [VALENCIA, ESPAÑA] ${ }^{(*)}$
}

\author{
THE SOCIAL ROLE OF LOCAL ARCHAEOLOGICAL HERITAGE. THE VALUE ENHANCEMENT OF \\ THE NECROPOLIS OF CALERILLA DE HORTUNAS DE REQUENA [VALENCIA, SPAIN]
}

\author{
KATIA SANTOS SÁNCHEZ ${ }^{[\star *]}$, BEGOÑA CARRASCOSA MOLINER $^{[\star \star)}$ Y ASUNCIÓN MARTÍNEZ VALLE $^{[\star \star \star *]}$ \\ Fecha de recepción: 15 de marzo de 2016 \\ Fecha de aprobación: 13 de abril de 2016
}

\begin{abstract}
RESUMEN
En Europa se pueden apreciar tres metodologías distintas en las técnicas de intervención y presentación del patrimonio arqueológico in situ: las reconstrucciones sobre los restos arqueológicos, llevadas a cabo fundamentalmente en los países nórdicos; las presentaciones tradicionales en forma de ruina, desarrolladas en los países mediterráneos; y los híbridos, utilizados indistintamente a través del viejo continente. De las tres tendencias se aprecia que la que contribuye a satisfacer tanto las necesidades de los enclaves como las del público, a la vez que ofrece una visión más próxima y social, es la primera. Las reconstrucciones de las estructuras in situ a partir de los materiales y técnicas originales, además de garantizar su sostenibilidad, también favorecen las finalidades sociales y educativas, lo que facilita considerablemente su interpretación. En España esta modalidad es escasa pero afortunadamente se cuenta con algunas excepciones. El proyecto de puesta en valor de la necrópolis de La Calerilla de Hortunas de Requena (Valencia, España) pretende ser una de ellas.
\end{abstract}

\section{PALABRAS CLAVE}

Educación patrimonial, reconstrucción in situ, empoderamiento cultural

\begin{abstract}
In Europe there are three different methodologies used in the intervention and presentation techniques of in situ archaeological heritage sites: reconstructions on the archaeological remains, carried out primarily in Nordic countries; traditional presentations in the form of ruins, developed in Mediterranean countries; and hybrids, used throughout the continent. Of the three trends shown, the one that best helps meet both the needs of the enclaves and those of the public, besides offering a closer social experience, is the first methodology. In situ reconstructions of structures based on the original materials and techniques ensure its sustainability, and also help develop its social and educational purposes, which greatly facilitates their interpretation. Even though this type is scarce in Spain, fortunately, there are exceptions. The project of value enhancement of the necropolis of La Calerilla of Hortunas in Requena (Valencia, Spain) aims to be one of them.
\end{abstract}

\section{KEYWORDS}

Heritage education, in situ reconstructions, cultural empowerment

(*) El presente artículo surge de las investigaciones de las tres autoras y forma parte de la tesis doctoral de la MSc. Katia Santos, en curso, titulada "Yacimientos arqueológicos en el medio rural. "La Calerilla" de Hortunas de Requena (Valencia); Investigación y metodología para su incoación, puesta en valor y difusión sostenible" para la obtención del grado académico de Doctor en Conservación y Restauración de Bienes Culturales de la Universidad Politécnica de Valencia, bajo la dirección de la Dra. Begoña Carrascosa. $\left.{ }^{(* *}\right)$ Licenciada en Historia (2011, Universidad de Salamanca), y máster en Conservación y Restauración de Bienes Culturales, es doctoranda en el Departamento de Conservación y Restauración de Bienes Culturales de la Universitat Politècnica de València. Es especialista en arqueología clásica. Desde 2007 ha colaborado en diversos proyectos arqueológicos, campañas de conservación y restauración de materiales, y yacimientos arqueológicos de carácter nacional. Ha realizado publicaciones en revistas especializadas y participado en comunicaciones a congresos nacionales e internacionales. Contacto: ksantsant@gmail.com

$\left({ }^{* * *}\right)$ Doctora en Bellas Artes (1995, Universitat Politècnica de València), desde 1992 es profesora titular del Departamento de Conservación y Restauración de Bienes Culturales de la Facultad de Bellas Artes en la Universitat Politècnica de València. Desde 1996 hasta 2000 ha sido Directora del Museo de Prehistoria y del Servicio de Investigación Prehistórica de la Diputación de Valencia. Ha participado y dirigido diversos proyectos de I+D+i (en España, Guatemala y Ecuador). Además, es miembro del Consejo Rector del Instituto de Conservación y Restauración de La Consellería de Cultura Educación y Ciencia de Valencia, y del Consejo Científico del Máster de Conservación y Restauración de Bienes Culturales de la Universitat Politécnica de València. Contacto: becarmo@crbc.upv.es

(***) Licenciada en Geografía e Historia (1989, Universitat de València) y máster en Arqueología (1992 Universitat de València), es la Arqueóloga Municipal del Ayuntamiento de Requena desde 1997. Ha dirigido numerosas excavaciones arqueológicas y publicado artículos en revistas de investigación de ámbito nacional e internacional. Ha impartido cursos en la Universidad de San Juan en Argentina sobre arqueología del vino y ha participado en congresos internacionales sobre Paisajes Culturales e Itinerarios Culturales en India, Vietnam, Argentina, Chile y Brasil. También es miembro de ICOMOS España y pertenece al Comité Internacional de Arqueología de ICOMOS. Contacto: museomunicipal@requena.es 
La diversidad de ámbitos culturales hace que, dependiendo del lugar en el que uno se encuentre, el patrimonio arqueológico local mantenga un significado diferente para cada comunidad. Las técnicas constructivas, los materiales y las tradiciones propias de cada área hacen que la relación establecida con dicho patrimonio difiera ampliamente. Se puede apreciar cómo los bienes culturales construidos a partir de adobes, madera o azulejo difieren considerablemente de aquellos creados sobre elementos pétreos (García Cuetos, 2009). Sucede así debido a que, a lo largo de su trayectoria, se establece un lazo entre la comunidad y el bien; la primera vela por la salvaguarda del segundo, que está sujeto a sucesivas reposiciones y reparaciones. Por el contrario, el patrimonio arqueológico erigido sobre materiales no perecederos -en el caso de Europa- se ha perpetuado intocable hasta prácticamente la actualidad. Se puede observar cómo esa relación y vinculación inicial, así como el factor sociocultural, se perdieron poco a poco en favor de su valor económico.

Según García Cuetos (2012), en el caso de Europa, antes de que la arqueología fuera constituida como ciencia y la restauración fuera siquiera mencionada, los que sentaron las bases para la forma de intervenir sobre el patrimonio fueron los dos grandes protagonistas de aquellos momentos: la llustración y el Romanticismo. De aquellos se gestaron la erudición y el anticuarismo, fuertemente influenciados por el valor de lo auténtico, la belleza y la monumentalidad. Estas condiciones preestablecidas fueron las ópticas que determinaron si la materia podría ser valorable o no. En este sentido, destacaban dos particularidades: la visión en forma de ruina de aquellos yacimientos considerados realmente importantes, y el rechazo a su restauración y reconstrucción volumétrica, principalmente en el área mediterránea. Primaban, por tanto, los yacimientos de época clásica, que, al estar constituidos por materiales inorgánicos y no perecederos, perdurarían en mejores condiciones. Estas ofrecían una belleza y monumentalidad que llamaba la atención de las instituciones. En Europa, salvo algunas excepciones, esas condiciones se daban en pocas ocasiones; por ello, el valor atribuido a las estructuras arquitectónicas era prácticamente inexistente, y prevalecía la importancia de los objetos-reliquia que de ellas eran extraídos. El valor social y los fines culturales para los que fueron edificados los monumentos considerados hoy nuestro patrimonio arqueológico local pasarían inadvertidos. Esta disciplina nació vinculada a los restos del pasado, pero no a la cultura popular. La cultura anticuarista occidental centró sus esfuerzos en los monumentos, y elaboró su teoría restauradora al servicio de ellos.

No ocurría lo mismo, como se podrá ver, en los países nórdicos europeos, donde aquellos enclaves arqueológicos que evocaban al pasado heroico fueron estrechamente vinculados a la población con carácter propagandístico en el siglo XIX. A diferencia de los países mediterráneos, estos enclaves eran reconstruidos volumétricamente, pero, como se planteó, sin perseguir fines sociales o didácticos inicialmente, sino fines propagandísticos.

Afortunadamente, esta situación ha evolucionado; en la actualidad existe un panorama de cambio que paulatinamente vela cada vez más por la puesta en valor, social y sostenible, de yacimientos arqueológicos. A través de las siguientes líneas, se darán a conocer los distintos tipos de intervención y presentación in situ promovidos hasta el momento, tanto en Europa como en España. Finalmente, se ofrecerá una visión desde la óptica social del patrimonio, y desde las experiencias que se están llevando a cabo en torno al yacimiento arqueológico de La Calerilla de Hortunas en Requena (Valencia, España).

\section{Principales tipos de intervención y presentación in situ en España}

En el campo de la conservación y restauración de los bienes arqueológicos inmuebles existen diversas formas de intervenir y presentar al público los yacimientos. Por un lado, las técnicas utilizadas han evolucionado considerablemente y el concepto de patrimo- 


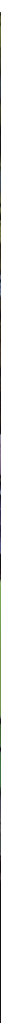

nio también ha sido ampliado. Pero por otro, existen diferentes opiniones acerca de los modus operandi empleados. En este apartado están recogidas las técnicas que abarcan desde la presentación tradicional hasta las reconstrucciones volumétricas. La evolución que se está produciendo en este último siglo hacia una visión más social y humana del patrimonio queda recogida en el transcurso de las cartas internaciones y el debate actual acerca de los criterios de intervención. Como afirma Ma P. García Cuetos, "si el siglo XX ha sido el siglo de las cartas, el XXI será el del diálogo" (García Cuetos, 2009, p. 46).

La necesidad de una revisión y reflexión de los criterios de intervención en la restauración arqueológica es obvia, sobre todo ante la presencia de un amplio abanico de formas de intervenir y transmitir el patrimonio arqueológico inmueble. Siguiendo las premisas de una investigación arqueológica que no permita perder ningún elemento, que ayude a comprender el sitio y que garantice su disfrute, los profesionales han elegido distintas vías: en primer lugar, la más explotada en España, la denominada 'presentación tradicional in situ', que muestra los restos tal cual fueron hallados; en segundo lugar, se encuentran los 'híbridos' o reconstrucciones parciales, una opción muy valorada en la actualidad, que responde a un consenso de criterios; finalmente, en tercer lugar, a raíz de los resultados tan positivos mostrados en los museos al aire libre del norte de Europa, las 'reconstrucciones volumétricas integrales'.

\section{Presentación tradicional in situ}

Se trata de la opción más extendida desde los inicios, fundamentalmente en los países mediterráneos. Es posiblemente la mejor valorada y aceptada hasta la actualidad por muchos profesionales. Su esencia hace referencia a una intervención mínima donde las estructuras arquitectónicas únicamente son consolidadas y se muestran al público prácticamente tal cual fueron halladas en las campañas arqueológicas. El sitio conserva la autenticidad de la fuente primaria sin ser manipulada (Santacana \& Masriera,
Figura 1. Puesta en valor y'musealización' del Parque del Molinete (Cartagena, Murcia)

Fuente: D. Frutos, 2012. 
2012). Esta metodología engloba una visión romántica y encapsulada del patrimonio arqueológico; considera preciso mostrar los yacimientos tal como han sobrevivido hasta nuestros días. Se perciben claramente los criterios internacionales de mínima intervención y rigurosidad histórica.

Por otro lado, se puede apreciar cómo la mayor transformación que sufren los enclaves sometidos a esta modalidad tiene que ver, a nuestro entender, con la colocación de cubiertas a modo de protección ante factores atmosféricos. Estas cubiertas no han seguido generalmente las líneas de los inmuebles y no han sido construidas con materiales respetuosos ni afines al original. Existen excepciones como las termas romanas de Camargo (Cantabria, España); allí la cubierta fue realizada a raíz del estudio llevado a cabo por M.L. Ramos sobre procesos de manufactura a través de la arqueología experimental, promovido por la Universidad de Cantabria (Ramos Sainz, 2004). Por lo general, este tipo de cubiertas no vinculantes hacen que nos paremos a pensar: en primer lugar, la protección que los emplazamientos tenían originalmente ha sido perdida en algún momento; y, en segundo lugar, se descontextualiza y distorsiona el enclave y el paisaje arqueológico, lo cual impide su correcta asimilación por el público. Podría decirse que a raíz de la presencia de estos añadidos la pervivencia de la voluntad purista y recreadora, y el miedo inicial a cometer los más mínimos errores, se han ido suavizando. Además, a partir de 1990 se ejecutaron numerosas intervenciones que provocaron cierta polémica, lo que coincidió con el fenómeno del alza en el sector inmobiliario. Se inauguraron, siguiendo esta metodología -sobre todo en las áreas más turísticas-, una cantidad ingente de yacimientos arqueológicos concebidos como productos financieros sin una planificación previa (Martín Piñol, 2013).

En consecuencia, en los enclaves presentados bajo esta lupa, que velan por los intereses científicos, no se aprecia una dimensión social que facilite al público su entendimiento, el cual puede realizarse a través de elementos auxiliares como cartelería, guías, etc. Tampoco se facilita su aprendizaje o educación patrimonial, ni la identificación con el pasado o la apropiación social del bien como elemento cotidiano (ver Figura 1).

\section{Híbridos o reconstrucciones volumétricas parciales in situ}

Si la modalidad descrita anteriormente era la más extendida desde los inicios en la presentación de yacimientos arqueológicos al público, sin duda los híbridos o reconstrucciones volumétricas parciales in situ son, en estos momentos, la salida más socorrida y mejor aceptada. Se trata de una posición intermedia y consensuada, en la cual los restos arqueológicos resultan más comprensibles que la opción anterior a través de su contextualización parcial. Estas reconstrucciones, en primer lugar, mejoran las condiciones de preservación de los restos; estos quedan protegidos y no se altera su'autenticidad'. En segundo lugar, sirven para que el visitante obtenga un mínimo de referencias visuales que le ayuden a comprender e interpretar los hallazgos. Aun así, las referencias no suelen ser suficientes para una correcta interpretación; esto hace que sea necesario contar con el refuerzo que los medios habituales proporcionan para facilitar su entendimiento, como cartelería, maquetas, guías, audioguías, etc. (ver Figura 2).

En cuanto a su denominación, las reconstrucciones parciales a menudo son denominadas 'consolidaciones' o 'anastilosis'. En realidad, la consolidación hace referencia al primer caso, que hemos denominado 'presentación tradicional in situ' porque la reconstrucción parcial, además de proteger los restos, influye considerablemente en su interpretación y aumenta la legibilidad (López-Menchero, 2013). El término'anastilosis', que implica la recolocación de los restos derruidos en su lugar originario, también ha sido muy utilizado para denominar esta metodología; es más, ha sido aceptado en las cartas internacionales de Atenas en 1931, en la Carta del Restauro de 1932, en la Carta de Venecia de 1964 e incluso en la Carta del Restauro de 1972. Sin embargo, a pesar de que en las posteriores cartas (como en la Carta de Burra de 1979, en la Carta de Lausana 


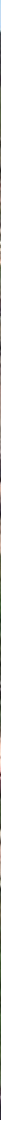

de 1990 o en la Carta de Cracovia del año 2000) el concepto fue desapareciendo paulatinamente, su uso ha continuado siendo muy común. En cualquier caso, en la opinión de varios autores -como Santacana, Masriera o López-Menchero- se entiende que anastilosis y consolidación evocan lo original, y que por ello han sido utilizados como eufemismos de 'reconstrucción', la cual haría referencia a la falsificación. La aceptación de 'reconstrucción' y su aplicación en materia patrimonial es aún un debate abierto.

Ante este panorama fue necesaria la revisión de los criterios internacionales, que han evolucionado y se han recogido en cada una de las cartas internacionales mencionadas. Se comenzó, así, con el criterio de mínima intervención. La ampliación de la matización de la referida intervención se puede observar cada vez más; a partir de la Carta del Restauro de 1972 se garantiza la intervención mínima necesaria para garantizar la estabilización y salvaguarda de los restos arqueológicos. El criterio de discernibilidad no pasaría desapercibido; en este la diferenciación entre materiales añadidos y originales era requerida con el fin de evitar falsificaciones históricas. Sin embargo, no queda del todo claro si dicha separación debe ser prácticamente inadvertible y únicamente visible para los profesionales, o si también debe ser visible para el público, como se interpreta en la Carta de Venecia, en el Art. 15\%:

"... los elementos de integración serán reconocibles y representarán el mínimo necesario para asegurar las condiciones de conservación de un monumento y restablecer la continuidad de sus formas." (Carta de Venecia, 1964)
Figura 2. Reconstrucciones parciales en Segóbriga (Saélices, Cuenca) Fuente: http://www.segobriga.org/, 2012. 
devenir Vol. 3, N5, ENERO - JUNIO 2016, PP. 9-27 - EstudIOS I ISSN 2312-7570

UNIVERSIDAD NACIONAL DE INGENIERÍ, LIMA

Figura 3. Yacimiento arqueológico de Eketorp (Ólland, Suecia)

Fuente: http://www.eketorp.se/, 2010.

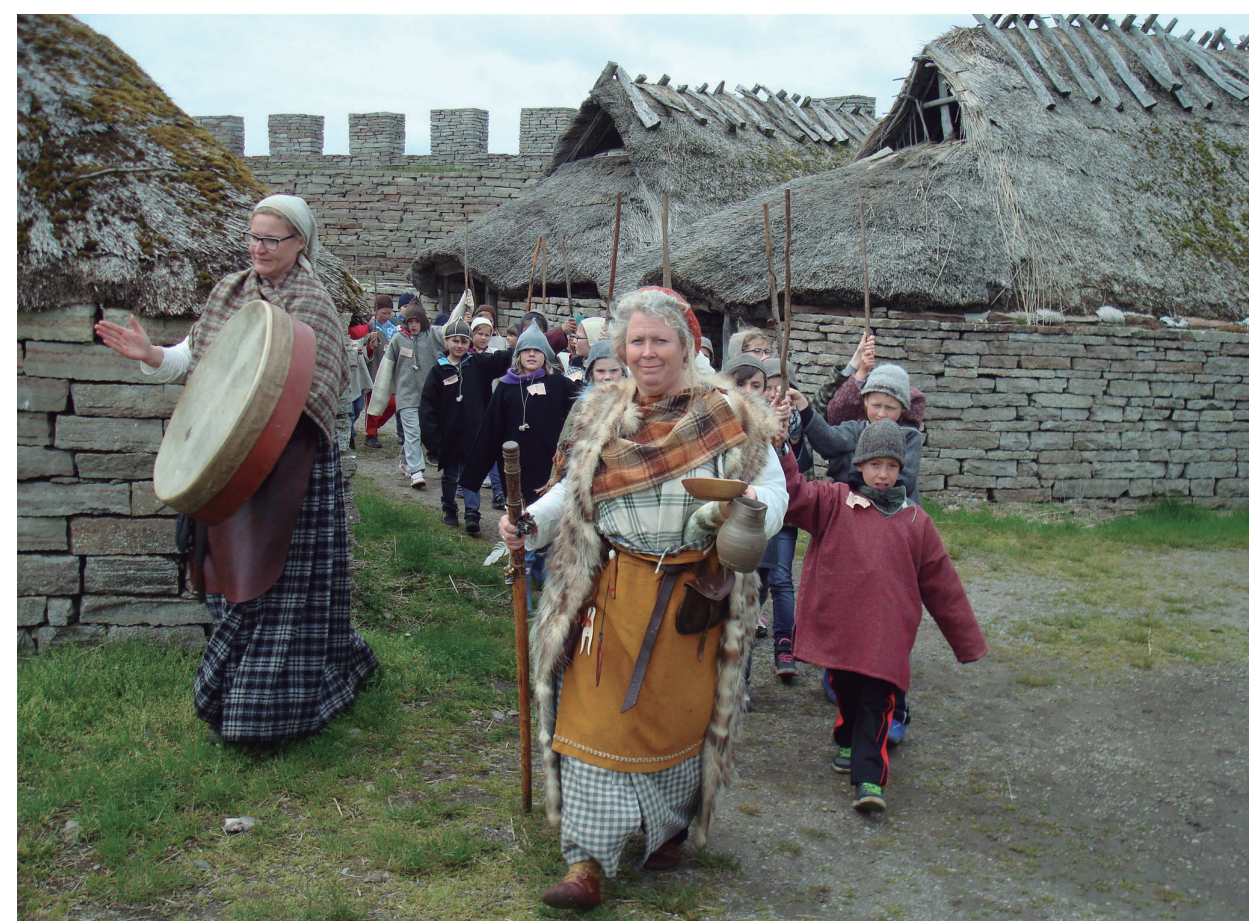

El aporte de la investigación arqueológica inicial y un estudio previo de la puesta en valor a cometer sobre el bien serían necesarios para el fin de garantizar una rigurosidad histórica que no lo desvirtúe ni provoque pérdidas irreparables. En consecuencia, también fue necesario revisar el criterio de reversibilidad y respeto hacia el original, ya que los añadidos en muchos casos no eran realizados empleando de materiales afines ni tampoco eran acordes con el entorno y el lugar.

Si bien esta modalidad tiene un trasfondo social al implicarse en la interpretación de los enclaves, la necesidad de consenso y de redefinición de este tipo de intervención también se da a raíz de los múltiples casos registrados en los que el principio de sostenibilidad y uso de materiales afines al original no se han cumplido.

\section{Reconstrucciones volumétricas integrales in situ}

Si se parte de la premisa de que estamos ante un constante proceso de cambios y de renovación, las reconstrucciones integrales se presentan como una alternativa de gran éxito desde los países nórdicos de Europa, iniciadas tradicionalmente en Alemania y Países Bajos. En cambio, en los países mediterráneos se ha mantenido prácticamente ausente, aunque se puede contar con alguna excepción, como se podrá ver en las siguientes líneas. A pesar de ser una técnica considerablemente antigua, sobre todo en el ámbito de restauración arquitectónica con Viollet Le Duc, en España no fue utilizada hasta 1955 (López-Menchero, 2013).

En ese sentido, como se dejaba ver en las primeras líneas, este tipo de intervención ha planteado desde sus inicios hasta la actualidad una gran controversia. En el ámbito internacional, a lo largo de su historia, ha quedado patente el uso de materiales insostenibles en distintos casos, lo que ha llegado a incluso poner en peligro de pérdida el patrimonio arqueológico. También se registraron ejercicios de reconstrucción planteados sin una base totalmente científica. Por ello, en las cartas internacionales y legislaciones de cada país, trataron de regular esta metodología estableciendo límites; incluso se llegó a impedir. Por otro lado, también se ha valorado su parte positiva, ya 


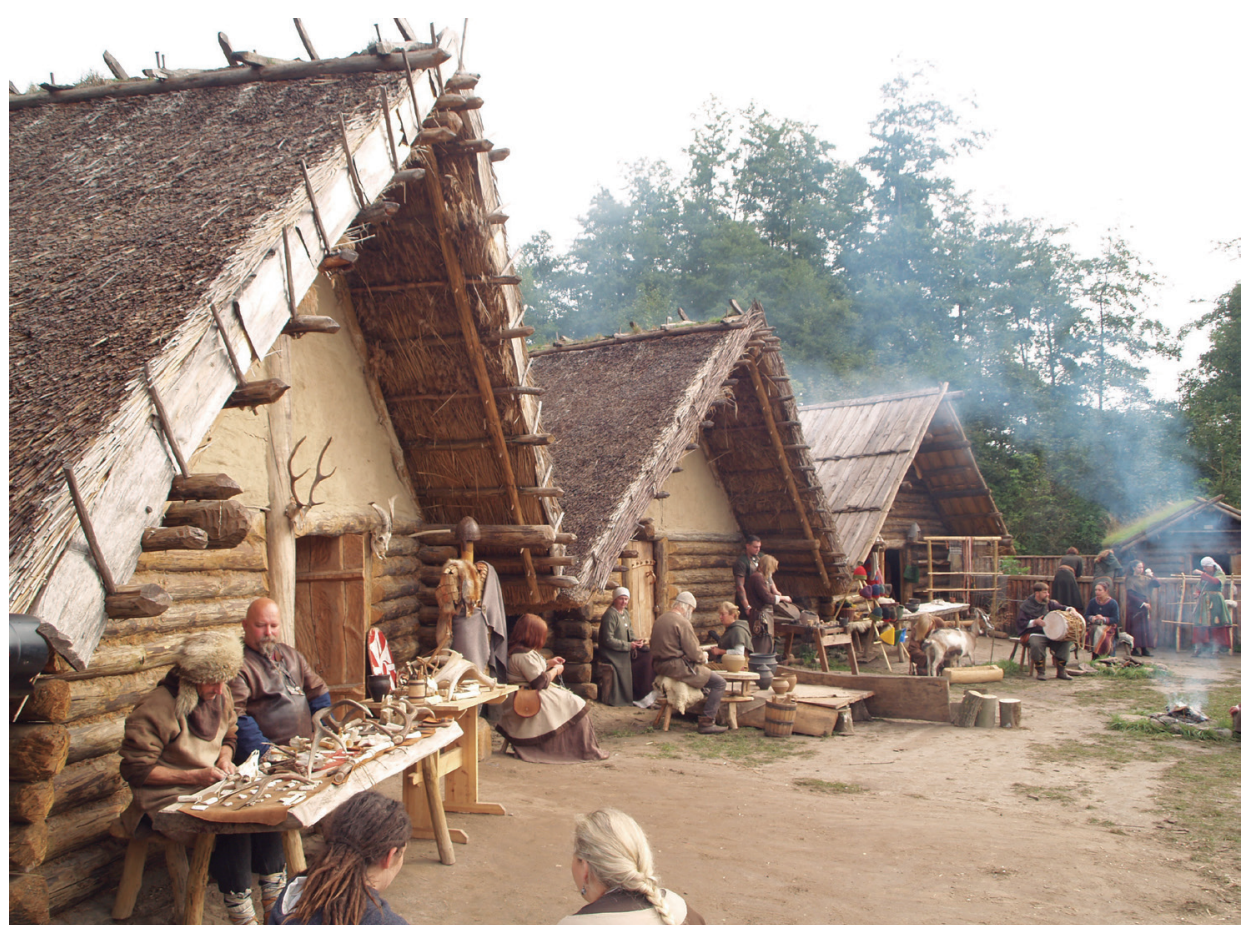

que existen casos importantes en los que ha resultado ser todo un éxito, como en el conocido poblado polaco de Biskupin o en el castillo sueco de Eketorp (ver Figuras 3 y 4). En ellos se cuenta con la protección del valor científico y se muestra el respeto por los restos originales desde el uso de técnicas tradicionales, las cuales, al adquirir gran atractivo para el público, llegan a ser autosuficientes.

La trayectoria se marcó inicialmente por la Carta de Atenas de 1931. Se puede decir que es el documento que más restringe este tipo de reconstrucciones, lo que se entiende como reacción a aquellas ya ejecutadas desde el siglo XIX. En el "Artículo II" se cita:

... a pesar de la diversidad de casos especiales en los que se pueden adoptar soluciones específicas, predomina en los diferentes Estados presentados, la tendencia general a abandonar las restituciones integrales y a evitar sus riesgos mediante la institución de obras de mantenimiento regular y permanente, aptos para asegurar la conservación de los edificios. En los casos en los que la restauración aparezca indispensable después de degradaciones o destrucciones, recomienda respetar la obra histórica y artística del pasado, sin menospreciar el estilo de ninguna época. (Carta de Atenas, 1931)

Tras la Segunda Guerra Mundial, resurgió el debate acerca de las reconstrucciones integrales en los países nórdicos a causa de la destrucción total de numerosas ciudades, especialmente en Alemania.

Mientras, en España, años después se mantiene un posicionamiento legal relativamente claro en relación a las reconstrucciones integrales; se percibe aún la influencia de la Carta de Atenas y naturalmente de la siguiente, la Carta de Venecia. Así, la Ley 16/1985 del 25 de junio, de Patrimonio Histórico Español, regulaba en su artículo 39.2 las reconstrucciones integrales (López-Menchero, 2013), donde indica lo siguiente:

En el caso de bienes inmuebles, las actuaciones a que se refiere el párrafo anterior encaminadas a su conservación, consolidación y rehabilitación y evitarán los intentos de reconstrucción, salvo cuando se utilicen partes originales de los mismos y pueda probarse su autenticidad.
Figura 4. Yacimiento arqueológico de Biskupin (Polonia)

Fuente: http://www.biskupin.pl/, 2014. 
Si se añadiesen materiales o partes indispensables para su estabilidad o mantenimiento las adiciones deberán ser reconocibles y evitar las confusiones miméticas ( Ley 16/1985, de 25 de junio, del Patrimonio Histórico Español, BOE de 29 de junio de 1985, Madrid, España).

En el artículo se hace hincapié en la técnica de anastilosis y no en la reconstrucción; igualmente, sigue sin citarse el fin sociocultural.

Además del criterio de discernibilidad, que es muy evidente, uno de los problemas a tener en cuenta era la reversibilidad, ante una reconstrucción que con el tiempo quede obsoleta. Ciertamente, podría darse el caso, en el transcurso de nuevas investigaciones arqueológicas, de que la teoría inicial formulada debiera ser modificada ante nuevas evidencias. Los profesionales se han planteado numerosas veces si realmente existe una reconstrucción reversible. Como es obvio, el miedo a realizar una inadecuada intervención es aún una constante, lo cual con el uso de técnicas tradicionales y sostenibles se puede reducir. En este sentido, la arqueología experimental realiza un ejercicio fundamental para conocer las técnicas y usos de nuestros antepasados; utiliza los recursos del medio natural a la vez que fomenta la sostenibilidad y la concienciación del público a través de la didáctica.

Esta última y la educación patrimonial cobran una grandísima importancia, lo que hace que el público esté más interesado en conocer cómo vivían las comunidades del pasado que en los restos arqueológicos en sí. Con esta práctica surge la posibilidad de transportarse al pasado, lo que provoca grandes reflexiones en el público. Se convierten en enclaves que permiten disfrutar del paisaje y el medio que le rodea, sin altos contrastes antrópicos.

Asimismo, es posible distinguir tres tipos de intervención y presentación al público dentro de las reconstrucciones volumétricas integrales in situ: reconstrucciones volumétricas in situ sobre las estructuras originales; ex situ, en el espacio inmediatamente adyacente; y las reconstrucciones volumétricas traslado, donde las reconstrucciones son realizadas también sobre estructuras originales, pero en un nuevo emplazamiento.

\section{Reconstrucciones volumétricas integrales in situ sobre los restos originales}

En España el primer yacimiento arqueológico que fue reconstruido por completo y sobre los restos originales, fue el de la Ciudadela Ibérica de Calafell en Tarragona (Cataluña), intervenido entre los años 1993 y 1994 por J. Santacana y J. Sanmartí (1995) (ver Figura 5). En él la influencia de otros enclaves internacionales, como el de Eketorp (Ölland, Suecia), es claramente apreciable. En este caso, con el fin de conseguir una intervención sostenible, respetable, social y adaptable a los criterios establecidos, se siguieron los principios de la Carta Internacional para la Gestión del Patrimonio Arqueológico de 1990 o Carta de Lausana, donde se expresa que

\footnotetext{
....las reintegraciones responden a dos funciones importantes: la investigación experimental y los fines pedagógicos e interpretativos de la realidad pretérita. Sin embargo, deben tomarse grandes precauciones para no borrar cualquier huella arqueológica subsistente; y deben tenerse en cuenta toda serie de pruebas para conseguir la autenticidad. Allí donde resulte posible y apropiado, tales reposiciones no deben efectuarse inmediatamente encima de los restos arqueológicos, y han de ser identificables como tales. (Carta Internacional para la Gestión del Patrimonio Arqueológico, 1990, p. 5).
}

Aun así, se cuenta con yacimientos en España en los que se han realizado reconstrucciones volumétricas integrales in situ sobre estructuras arqueológicas aisladas. La primera reconstrucción de este tipo tuvo lugar en el yacimiento arqueológico de Los Millares (Santa Fe de Mondújar, Almería), referente en Europa en la época del Calcolítico. Únicamente fue realizada sobre la tumba 17 de tipo tholoi, desarrollada entre los años 1953 y 1956 por Almagro y Arribas (AA.VV., 2008) (ver Figura 6). En Galicia también se realizaron reconstrucciones aisladas en el Castro de Elviña (A Coruña) en 1957, y tras 

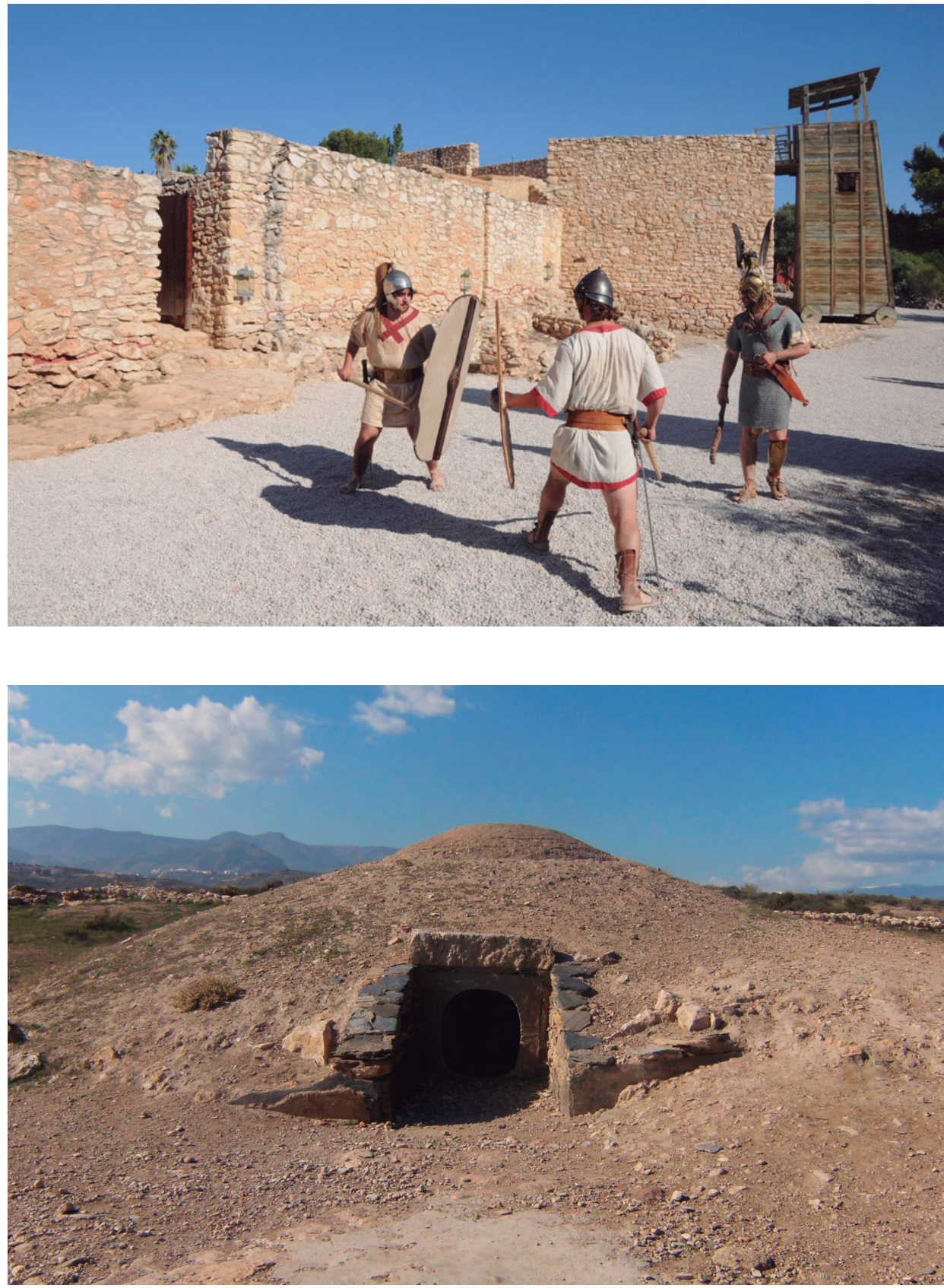

su éxito en Santa Tegra (A Guarda, Pontevedra), en 1965 y 1972. El primer caso llevado a cabo por los arqueólogos L. Monteagudo y J. Ma Luengo fue lamentablemente destruido a causa de un incendio (López-Menchero, 2013; Ayán, 2001).

A partir de 1960, se deben tener en cuenta las intervenciones de rehabilitación sobre los teatros romanos en España (AA.VV., 2011), con un claro matiz: a diferencia de las reconstrucciones, las rehabilitaciones buscan recuperar la función original y reutilizar el espacio con el fin de darle el uso para el que fue concebido. Las reconstrucciones, más bien, son realizadas para poder admirar y comprender el uso que se le dio en su momento. En este marco se encuentra la rehabilitación del teatro de Mérida, llevada a cabo por el equipo del arqueólogo y arquitecto Menéndez Pidal, entre los años 1964 y 1970. Gra-
Figura 5. Ciudadela de Calafell Fuente: http://www.calafellhistoric. org/,2014.

Figura 6. Reconstrucción de una tumba tipo tholoi en el yacimiento arqueológico de Los Millares (Santa Fe de Mondújar, Almería)

Fuente: Archivo fotográfico personal Katia Santos, 2014. 
cias al abundante material constructivo localizado del frente de la escena y las gradas, pudo levantar por anastilosis las partes fundamentales. Los errores históricos documentados posteriormente y tratados con materiales irreversibles (AA.VV., 2011) no fueron tan relevantes como los cometidos en el teatro romano de Sagunto a partir de 1986. La rehabilitación realizada por Grassi y Portaceli marcó un antes y un después en la historia del patrimonio español. El uso de materiales irreversibles tanto en la escena como en el graderío es palpable, lo que potencia una interpretación estética frente a la histórica.

Después de este episodio y con respecto a las reconstrucciones, a partir de 1994 está el caso del yacimiento arqueológico de Numancia (Garray, Soria), del siglo III a.C. En este yacimiento se realizaron las reconstrucciones in situ de dos viviendas (una celtibera y otra romana), además de un tramo de muralla con materiales tradicionales y sostenibles. Asimismo, la celebración de las batallas numantinas año tras año, con los guiones ajustados a los episodios narrados por Apiano, cumplen una gran labor educativa (Jimeno, 2013).

\section{Reconstrucciones volumétricas integrales ex situ}

Este apartado está dedicado a aquellas reconstrucciones que se realizan en el entorno inmediato al yacimiento arqueológico sin intervenir directamente sobre los restos arqueológicos.

Son cada vez más los yacimientos que, para atender a fines didácticos, se decantan por esta acción emergente. Se trata de una opción más cómoda que la anterior, ya que, sin necesidad que profesionales que reconstruyan los originales, el público puede comprender los hallazgos al compararlos con los ejemplos reproducidos. Aun así, tanto los restos originales como la reproducción son presentados al público en espacios separados que, sin la ayuda de infraestructuras para la interpretación (como cartelería, guías, audioguías, etc.), pueden ser difíciles de relacionar. Aun teniendo referencias para interpretar más fácilmente los restos, igual se está ante un yacimiento en forma de ruina. En todo caso, se altera el paisaje: para intervenir siguiendo estos parámetros es indispensable contar con un espacio adyacente en el mismo enclave, donde existan también garantías de que bajo él no se encuentren más restos arqueológicos.

En la provincia de Valencia se cuenta con un yacimiento que reúne estas características. Se trata de la Bastida de Les Alcusses de Moixent, ciudad ibérica fortificada del siglo IV a.C., que fue declarada Monumento Histórico-Artístico en 1931. En las afueras del asentamiento se ha reproducido y recreado una de las casas más representativas de la cultura ibérica, la cual está destinada a actividades didácticas y talleres experimentales desde 1999. Reproduce los espacios del núcleo central de las viviendas ibéricas e incluye un vestíbulo, una sala principal, un área de molienda y cocina, y un patio y un almacén, que ocupan un total de $340 \mathrm{~m}^{2}$. Esta fue realizada utilizando las mismas técnicas de construcción tradicionales a partir de adobes y de cubiertas vegetales (Bonet y Vives-Ferrándiz, 2011), cuya copia puede visitarse en el Museu de Prehistòria de València (ver Figura 7).

También es importante la reproducción a escala de una domus romana en las proximidades de la ciudad romana de Julióbriga (Retortillo, Cantabria), conocida como la Casa de los Morillos, hoy el Museo de la domus romana. Fue erigida a partir de los restos arqueológicos de la domus original del siglo I. d.C., que ya se conocía en su totalidad desde el año 1956 a raíz de las distintas campañas arqueológicas. La casa-museo reproducida abrió sus puertas en el año 2003, con el objetivo de facilitar al visitante su interpretación y de mostrar los objetos arqueológicos hallados (Gil \& Cepeda, 2004).

Cronológicamente, el siguiente yacimiento relevante tratado con esta metodología es el ya citado anteriormente, Los Millares de Santa Fe de Mondújar (Almería). En él es posible encontrar, desde el año 2005, un pequeño parque próximo al yacimiento, donde se reproducen los hallazgos más emblemáticos del enclave con ambientación propia. 

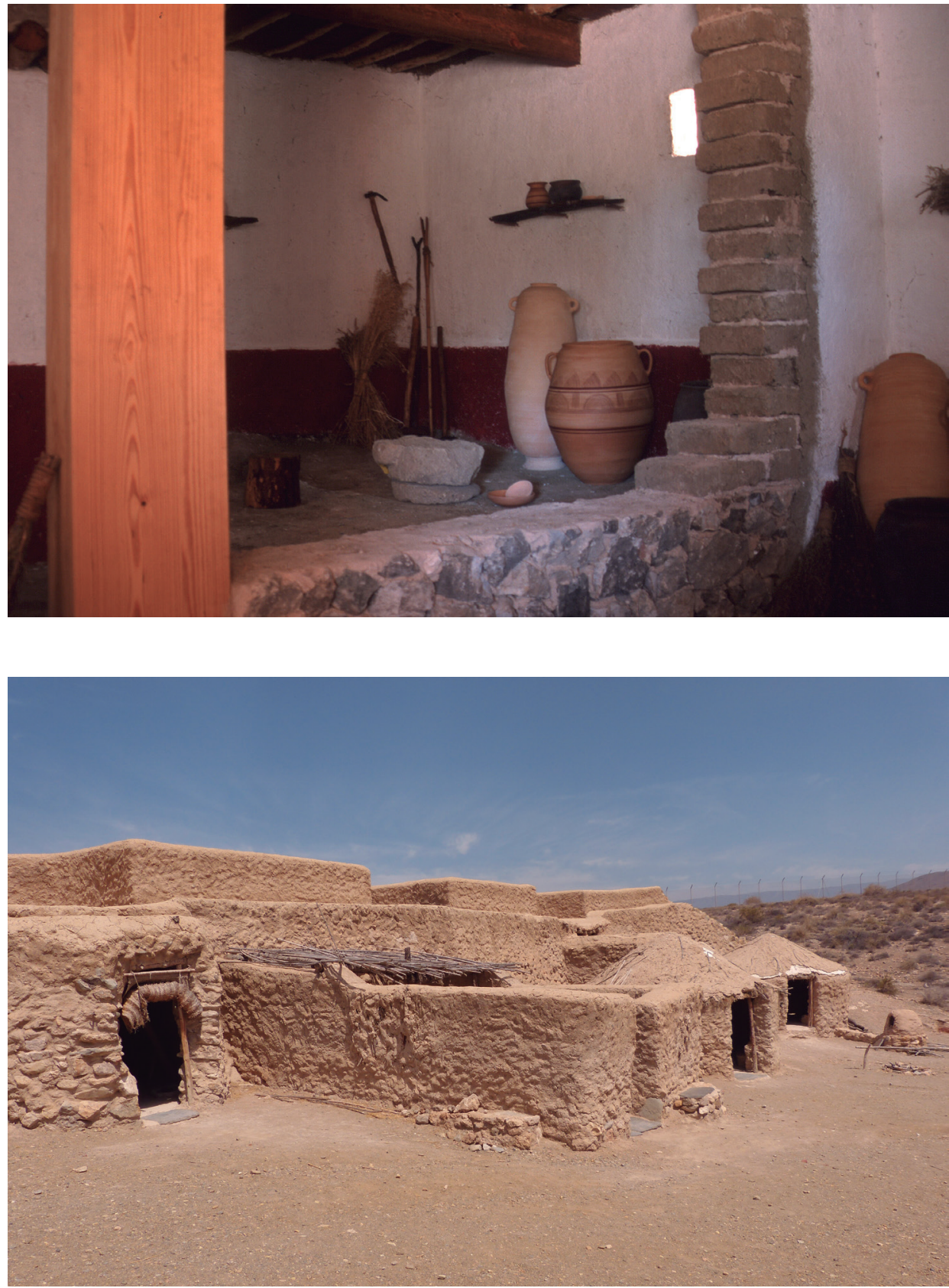

Entre ellos destacan: parte de la muralla, dos tholoi funerarios, un taller metalúrgico, dos cabañas y un corral (AA.VV., 2008). Naturalmente, para la construcción de estos espacios se han respetado los resultados obtenidos en las sucesivas investigaciones arqueológicas, y se han empleado herramientas primitivas y productos naturales (Moreno \& Haro, 2006) (ver Figura 8).

Igualmente, ha de tenerse en cuenta el Museo de las Villas Romanas en Almenara-Puras en Valladolid, que abrió sus puertas en el año 2003. En él se pueden visitar los restos musealizados de una villa romana bajo-imperial del siglo IV que fueron localizados en 1887. Además, desde el año 2008 se cuenta también con la reproducción a escala de una pars urbana, en la que se pueden visualizar la arquitectura y los
Figura 7. Reproducción y recreación de una casa ibérica en el yacimiento arqueológico de La Bastida de les Alcusses de Moixent (Valencia)

Fuente: http://bastidaalcusses.es/, 2014.

Figura 8. Reproducción de las partes más representativas del yacimiento arqueológico de Los Millares (Santa Fe de Mondújar, Almería)

Fuente: Archivo fotográfico personal Katia Santos, 2014. 
devenir Vol. 3, N5, ENERO- JUNIO 2016, PP. 9-27 - EstUdIOS I ISSN 2312-7570

UNIVERSIDAD NACIONAL DE INGENIERÍ, LIMA

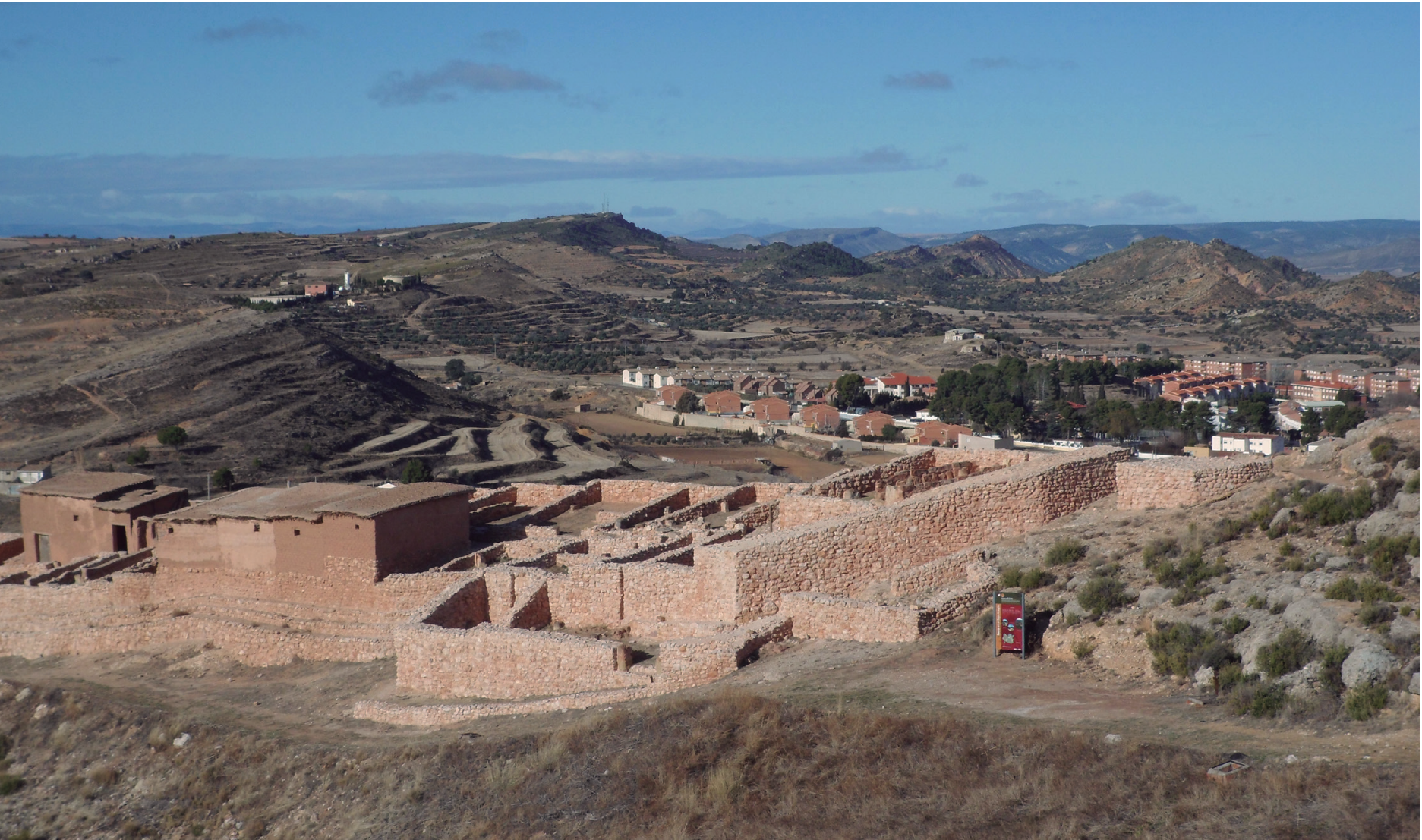

Figura 9. Vista del yacimiento arqueológico de El Cabo (Andorra, Teruel)

Fuente: www.patrimonioculturaldearagon.es, 2014 modos de vida rurales. A través del peristilo se accede a los ambientes de recepción y banquetes, un dormitorio, las termas y las habitaciones de la servidumbre. Es un edificio que ocupa un área de más de $650 \mathrm{~m}^{2}$ en un espacio separado pero próximo al museo (Fuentes et al., 2010).

\section{Reconstrucciones volumétricas integrales traslado}

La diferencia entre las intervenciones ex situ y los traslados también reside en que en determinadas ocasiones existen necesidades de urgencia, donde el yacimiento en cuestión sufre una situación de peligro de pérdida y la única forma de conservarlo es trasladándolo a otro lugar. Se incluyen dentro del grupo de intervenciones in situ, porque a pesar de que los restos son trasladados a un nuevo emplazamiento, la reconstrucción volumétrica se sigue realizando de forma íntegra sobre los restos originales.

En esta modalidad en España se cuenta con el poblado ibérico de El Cabo de Andorra (Teruel) del siglo $V$ a.C. La integridad del enclave se encontraba en peligro debido a su proximidad a una explotación minera de carbón propiedad de la empresa Endesa. Por esta razón, las estructuras más representativas del yacimiento fueron desmontadas parte por parte y trasladadas a su nuevo emplazamiento. El yacimiento fue destruido finalmente en 1999. Su traslado y 'reconstrucción' ${ }^{\prime}$ en lo alto del cerro de San Macario, en la misma localidad andorrana, no finalizó hasta el año 2004 (ver Figura 9). En este

1. En este caso, el término'reconstrucción' realmente se interpreta como construir los restos tal como fueron hallados; no obstante, sí ocurre un cambio en su contexto. Por tanto, esta reconstrucción no es mencionada entre las reconstrucciones volumétricas integrales a las cuales nos referimos en este capítulo. 


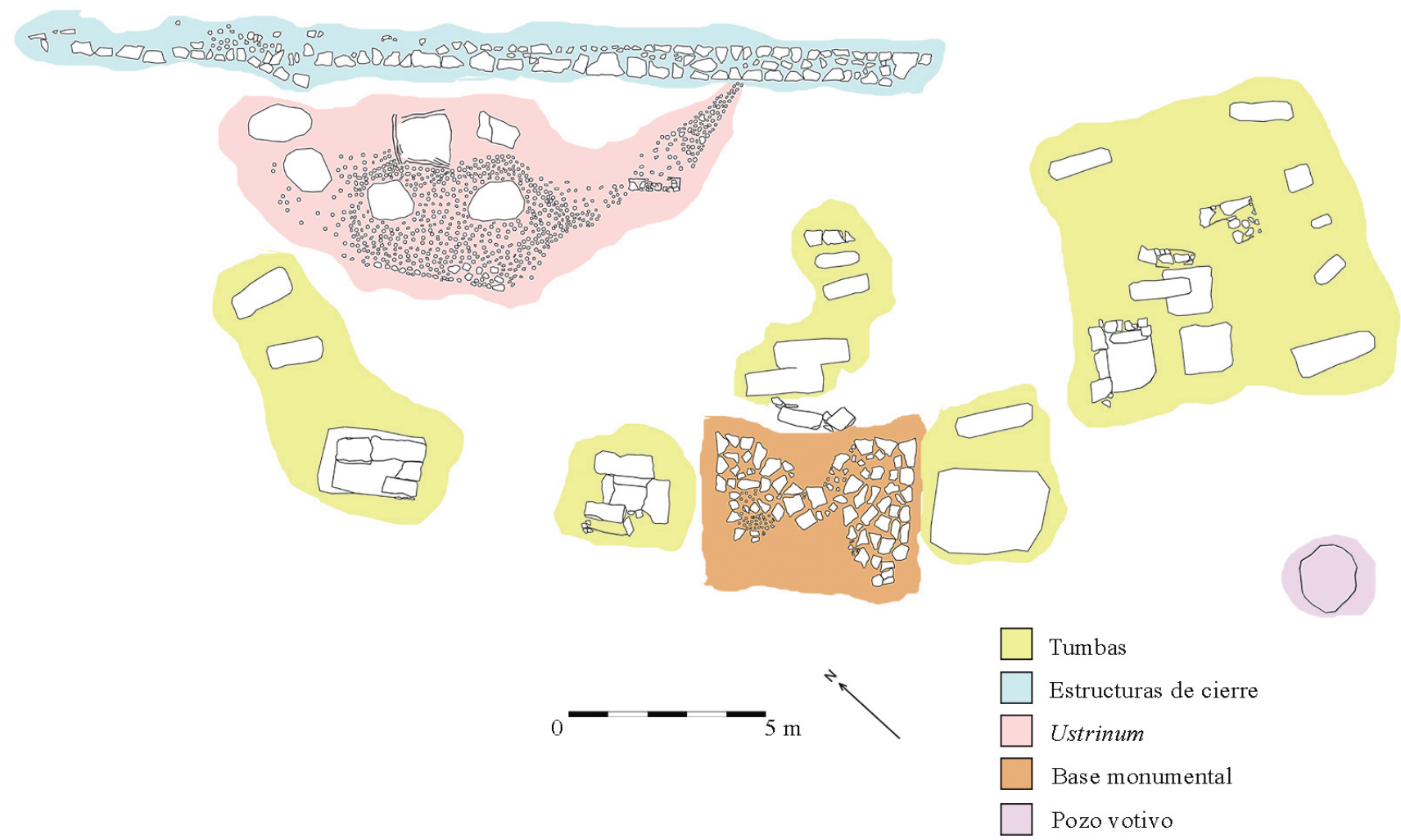

caso, se aprovechó la oportunidad del traslado para trabajar con técnicas de construcción actuales no necesariamente reversibles, a diferencia de los casos anteriores. Estas permanecen ocultas bajo paramentos de mampostería, adobes, enlucidos de barro y cubiertas vegetales. Las investigaciones arqueológicas, además, han permitido la reconstrucción completa de viviendas ibéricas en el emplazamiento a escala natural (ver Figura 9). Esta recreación del espacio exterior e interior cumple el objetivo previamente planteado: ofrecer al público una secuencia didáctica que incluya las diferentes fases del enclave, como el proceso de construcción, el abandono, la excavación, el traslado y la reconstrucción del propio yacimiento (Galve \& Benavente, 2004).

\section{La necrópolis arqueológica de La Calerilla de Hortunas de Requena (Va- lencia, España): un proyecto social y sostenible}

La necrópolis arqueológica de La Calerilla de Hortunas de Requena (Valencia, España) presenta una gran relevancia científica a partir del hallazgo de la parte central de una necrópolis altoimperial romana del siglo I d.C. El hallazgo se produjo en 1989 a raíz de los trabajos agrícolas que entonces se realizaban en este lugar. A partir de 1990 comenzaron las campañas arqueológicas anuales, hasta que en el año 2000 fueron interrumpidas y el yacimiento quedó abandonado.

Según las investigaciones realizadas por la arqueóloga municipal, actualmente el enclave está caracterizado principalmente por una base monumental, tumbas de cremación, estructuras de cierre y contención, un pozo votivo y el ustrinum (Martínez, 1995) (ver Figura 10). Los estudios realizados hasta el momento indican la evidente presencia de un monumento funerario que se alzaría sobre la base monumental. Así
Figura 10. Planimetría de la necrópolis de La Calerilla de Hortunas de Requena (Valencia, España)

Fuente: Archivo fotográfico Asunción Martínez y Katia Santos, 2015. 
devenir Vol. 3, N5, ENERO - JUNIO 2016, PP. 9-27 - ESTUDIOS I ISSN 2312-7570

UNIVERSIDAD NACIONAL DE INGENIERÍ, LIMA

Figura 11. Alzado hipotético del monumento funerario

Fuente: Archivo fotográfico Asunción Martínez y Katia Santos, 2015.

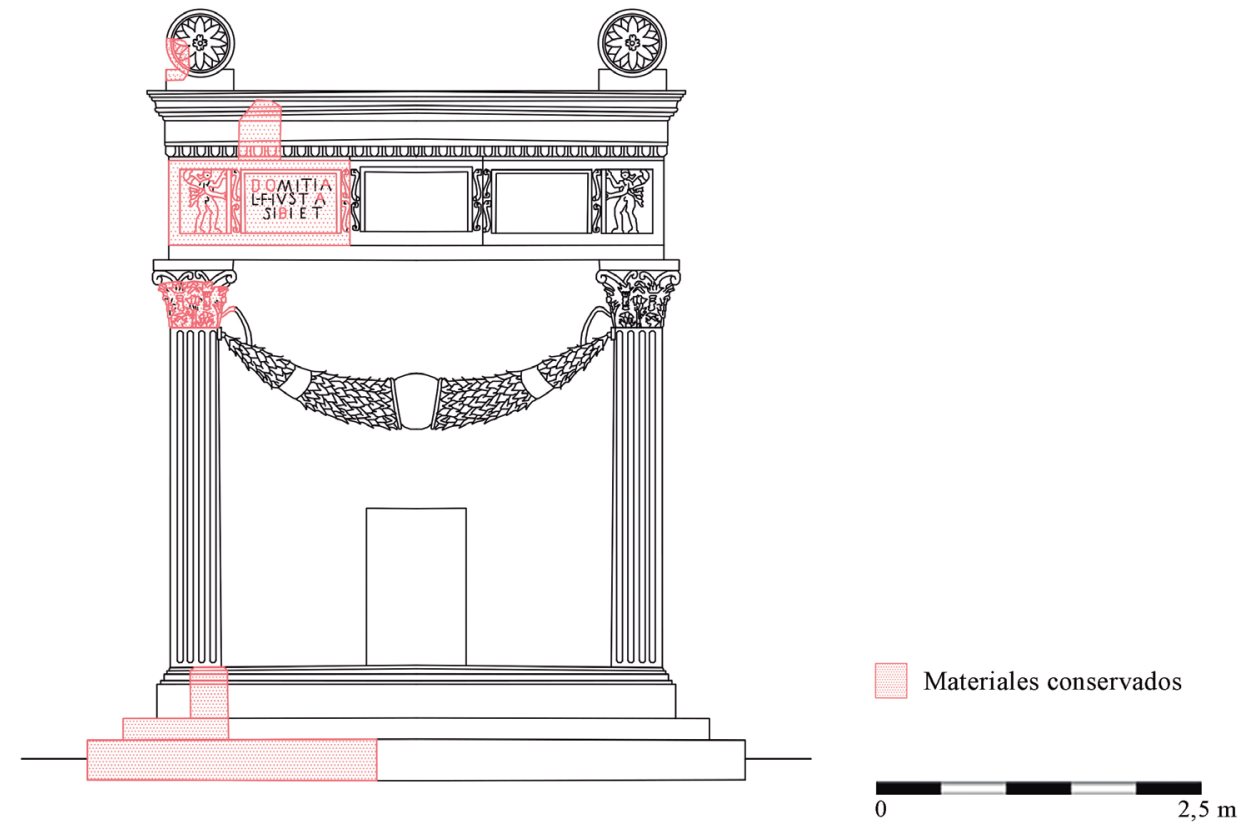

lo avalan materiales arquitectónicos, como una inscripción funeraria que nos rebela el nombre de su propietaria -Domitia lusta- (Martínez, 1991); un capitel corintio con forma de esquina; y elementos decorativos de coronación, como un pulvino de los dos que debió tener, así como abundante material constructivo, también cerámico y óseo (Garcerá Martínez, 1993; Martínez et al., 1993) (ver Figura 11).

El estudio de los materiales y técnicas constructivas en la ejecución de las estructuras del enclave nos da a entender que estarían compuestas por bloques de caliza terciaria, de origen lacustre de color gris y procedencia local. El cuerpo del monumento tendría una estructura constituida a partir de la técnica de ejecución opus caementicium, forrada por bloques de las mismas características que aquellos que formarían un paramento de opus cuadratum (Martínez, 1995). Los mampuestos que conformaron estas estructuras fueron trabados mediante material cementante compuesto por cal hidráulica, tierra y cantos rodados de distintos tamaños.

Con el paso del tiempo, su abandono a la intemperie y la falta de protección, el enclave sufre y se encuentra en un estado de degradación muy alarmante, lo que hace que factores de naturaleza climática, biológica y antrópica incidan sobre las estructuras. El debilitamiento de las mismas se puede observar perfectamente a través de excoriaciones, erosión mecánica y alveolización de los elementos pétreos; disgregación y debilitamiento de los morteros; enraizamiento y proliferación, principalmente, de vegetación y fauna (ver Figuras 12 y 13).

Por otro lado, la situación que atraviesa el enclave no favorece la vinculación entre el yacimiento y la población requenense, que la segunda se identifique con el primero. La difusión que se hizo en el momento de su hallazgo, a través de sucesivas campañas arqueológicas en la década de 1990, hoy se encuentra casi sin efecto (Santos, Martínez \& Carrascosa, 2015). Su inaccesibilidad tanto física como intelectual imposibilita su comprensión e interpretación, por lo que el interés por el enclave se ha visto perjudicado. 

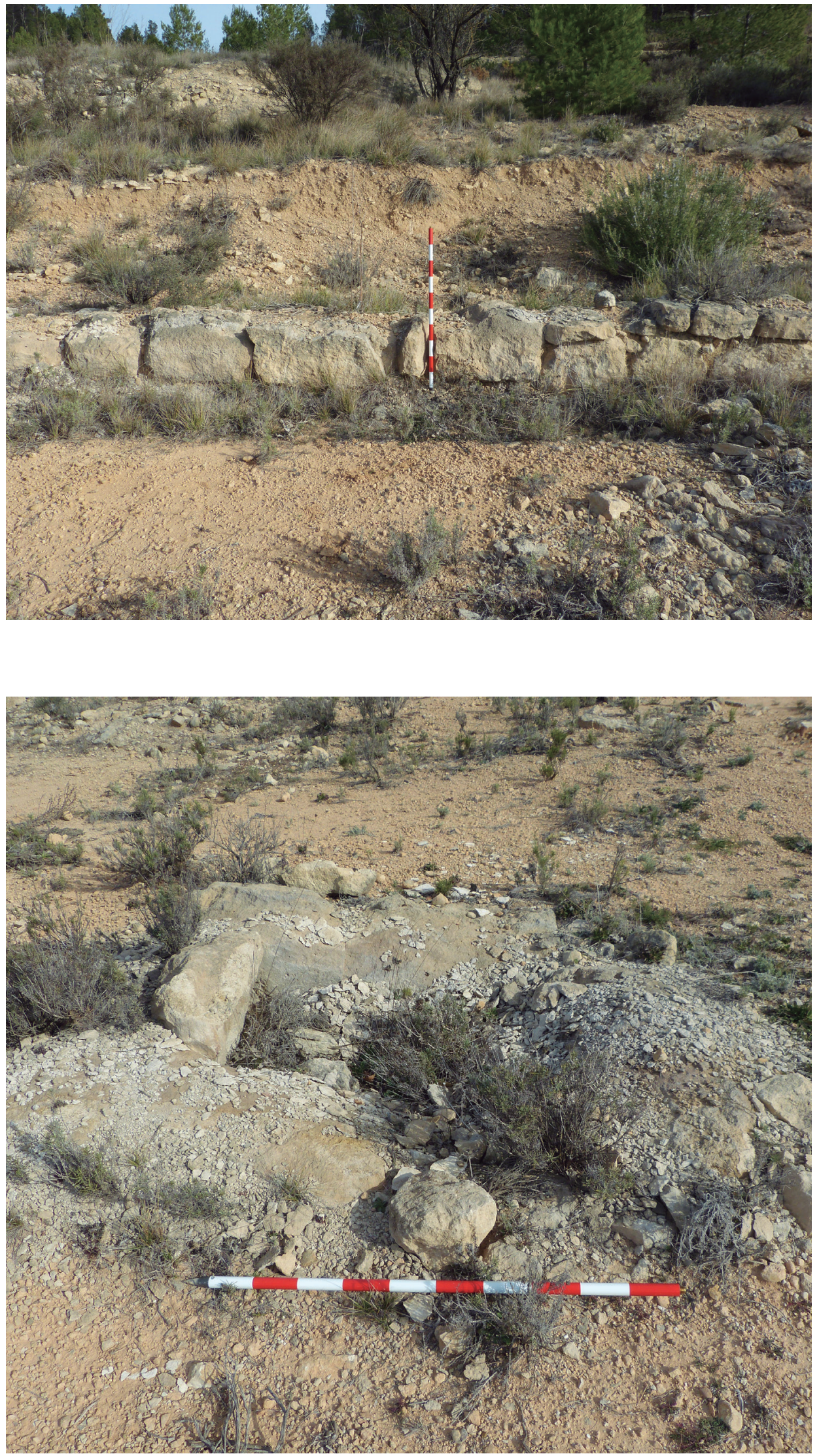

Figura 12. Estado de conservación actual del enclave: proliferación de la vegetación y debilitamiento de las estructuras de cierre

Fuente: Archivo fotográfico personal Katia Santos, 2015.
Figura 13. Estado de conservación actual de una de las tumbas de cremación

Fuente: Archivo fotográfico personal Katia Santos, 2015. 


\section{Planteamiento y justificación del proyecto}

Con el fin de poner en valor y conservar un yacimiento tan relevante como es el de La Calerilla de Hortunas, y fomentar el desarrollo social, científico y económico del municipio, se han establecido las bases de este proyecto de intervención arqueológica in situ según el aspecto social y sostenible del sitio. Para conservar los restos arqueológicos y, a su vez, presentarlos al público de tal modo que se fomente su educación patrimonial e identificación social, el equipo científico interdisciplinar ha considerado como mejor solución para el entendimiento de las actuales ruinas la reconstrucción volumétrica in situ sobre los restos originales. La reconstrucción de las estructuras se ha planteado bajo el aspecto científico del recrecimiento volumétrico y formal de las partes incompletas más relevantes que, a su vez, eran las que en peor estado de conservación se hallaban: la base monumental, y las estructuras de cierre y contención.

Por ello, teniendo en cuenta la legislación, cartas internacionales y la base metodológica expuesta, se han planteado los siguientes criterios de intervención a seguir durante la ejecución del proyecto:

- Las actuaciones a realizar estarán basadas en las investigaciones arqueológicas previas, y las que se están realizando en estos momentos sobre los materiales y técnicas originales de ejecución en el Instituto de Restauración del Patrimonio de la Universitat Politècnica de València. La vectorización de planos de las primeras excavaciones arqueológicas, la digitalización de las estructuras tal cual fueron localizadas y el diseño del proyecto con las futuras reconstrucciones in situ ofrecerán información detallada para futuras investigaciones. De esta forma, se podrá contribuir a la rigurosidad histórica sin que se produzcan desvirtualizaciones, modificaciones o pérdidas irreparables.

- El respeto hacia las estructuras originales será palpable a través de una intervención mínima que garantice su estabilidad. Únicamente se realizarán limpiezas mecánicas superficiales sobre los originales para liberarlos de concreciones, vegetación y posibles anidamientos, evitando siempre la pérdida de posible información. Asimismo, las reconstrucciones in situ serán realizadas sobre los restos, pero utilizarán materiales de separación que eviten dañar los originales y, a su vez, no debiliten el agarre de los morteros.

- Se utilizarán los materiales y técnicas empleados por los antiguos pobladores del lugar (sobre la base de resultados obtenidos de la investigación en curso en el Instituto de Restauración del Patrimonio de la UPV); entre estos, se encuentra el uso de elementos pétreos de caliza que se aprovecharán de los derrumbes y terreras, y la elaboración de morteros naturales para la ejecución de la técnicas de opus cuadratum y opus caementicium. Con ello, en el caso de que en un futuro fuera necesaria su eliminación si las nuevas investigaciones arrojaran datos que pusieran en entredicho la actual teoría, esta sería posible gracias a la reversibilidad de las actuales técnicas y morteros empleados.

- Con el fin de garantizar la autenticidad de los restos y su discernibilidad entre el original y el añadido, se utilizarán técnicas de diferenciación. Estarán fundamentadas en el uso de piezas testigo de realización exclusiva con indicadores direccionales para señalar la zona recrecida e indicador cronológico para señalar el año de la intervención. Estas piezas se colocarán longitudinalmente a través de las zonas de contacto entre originales y añadidos; esto garantizará, por un lado, su armonía y discreción, y, por otro, su detección tanto por los profesionales como por el público en general, lo que evitará los falsos históricos.

- El equipo de trabajo interdisciplinar estará constituido por expertos de ámbitos muy dispares en materia patrimonial, procedentes tanto de la Universitat Politècnica de València como del Museo Municipal de Requena. Arqueólogos, historiadores, conservadores-restauradores -hasta gestores y especialistas en pedagogía y didáctica- harán que sea posible alcanzar una mayor dimensión consensuada y contrastada. Además, para llevar a cabo los estudios de análisis, tanto del paraje como del medio en 
el que se encuentra el enclave, es necesario contar con la colaboración de geógrafos, biólogos y geólogos. También será de gran ayuda la presencia de químicos, quienes ayudarán en el análisis e interpretación de la composición de los materiales originales; esto facilitará su restauración con materiales afines y respetuosos.

- Gracias a la cómoda ejecución de las técnicas de construcción originales y el uso de los materiales de procedencia local y bajo coste, se certificará la durabilidad y sostenibilidad del enclave a largo plazo. A través de la supervisión periódica de las intervenciones, y de las campañas de conservación y restauración anuales programadas, se garantizará el futuro mantenimiento y estabilidad del sitio, lo que hará posible contribuir a su salvaguarda. De esta forma, se evitarán los clásicos errores cometidos en España durante la década de 1990, donde se ejecutaron proyectos insostenibles a largo plazo.

- Este proyecto cumplirá la finalidad para la que fue planteado:

- Paralizar y evitar el proceso de degradación en el que se ve envuelto el enclave, para contribuir a la conservación de los restos.

- Favorecer la presentación de los restos haciendo que el público pueda trasladarse a la Hispania romana del siglo I d.C. Con esta iniciativa se podrán regenerar los vínculos entre comunidades del pasado y del presente, y conseguir que la población sea partícipe. Asimismo, el interés por proteger y conservar su patrimonio será mayor, y mayor será también el empoderamiento cultural y el desarrollo científico que se produzca en la comunidad.

- Estimular la investigación científica, lo que permite el avance fundamental de la Arqueología Experimental.

\section{Conclusiones}

Somos conscientes de que la 'visión anticuarista' a la que se ha hecho referencia aún perdura en la actualidad; sin embargo, existen otras alternativas que velan por el fin social de nuestro patrimonio arqueológico local: las reconstrucciones integrales. Las nuevas técnicas de intervención y presentación in situ, que tienen importante impacto social, han despertado un verdadero interés, concienciación y sensibilización del público hacia su patrimonio. En aquellos casos en los que se han desarrollado este tipo de intervenciones en Europa y en España (en la Ciudadela de Calafell, Tarragona), se puede ver claramente ese despertar (Masriera, 2007). Mientras, se puede afirmar que la metodología tradicional de intervención en el patrimonio está siendo seriamente cuestionada, ya que no ha contribuido a favorecer el interés del público ni ha conseguido establecer vínculos identitarios.

Por otro lado, si se analizan detenidamente las cartas internacionales, en ellas se menciona lo esencial que es presentarle al público su patrimonio arqueológico, lo que teóricamente impulsaría un proceso de democratización cultural. Pero en la práctica, y hasta el momento en España, son escasos los ejemplos sociales con los que se puede contar. Además, si se parte de que el patrimonio es una herencia de los antepasados y pertenece a la sociedad, es ilógico que el público no cuente con los medios necesarios para poder participar y disfrutar de su patrimonio.

A decir verdad, el miedo a intervenir directamente sobre el patrimonio, a raíz de malas experiencias como la ocurrida en el teatro romano de Sagunto, aún está presente en España. En este sentido, el impulso de técnicas tanto tradicionales como sostenibles que se desarrollen en yacimientos erigidos sobre materiales perecederos ofrece una gran garantía de éxito y reversibilidad. De esta forma, además de realizar investigaciones conjuntas entre arqueólogos, arquitectos y conservadores-restauradores, también será necesario contar con artesanos y expertos de otras disciplinas que garanticen el cumplimiento del criterio de interdisciplinariedad, y se pueda ofrecer así una imagen mucho más científica, rigurosa y didáctica. 
devenir Vol. 3, N5 5, ENERO- JUNIO 2016, PP. 9-27 - ESTUDIOS I ISSN 2312-7570

UNIVERSIDAD NACIONAL DE INGENIERÍ, LIMA

Finalmente, a partir de las experiencias vividas hasta el momento en el enclave de La Calerilla, es posible afirmar que las técnicas aquí presentadas contribuyen a una mejor contextualización y comprensión de los restos. Adaptarse tanto a las necesidades conservacionistas del enclave como las de disfrute del público hacen que se favorezca considerablemente, además, la finalidad económico-turística. A diferencia de las técnicas tradicionales de presentación de los hallazgos en forma de ruina, los modelos de reconstrucción in situ pueden alcanzar una gran transcendencia en este sector. Así, con este nuevo enfoque se espera que La Calerilla pueda llegar a convertirse en un lugar vivo donde se fortalezcan los lazos de unión entre culturas del pasado y del presente.

\section{Referencias}

Bonet, H. \& Vives-Ferrándiz, J. (Eds.), (2011). La Bastida de Les Alcusses 1928-2010. Valencia, España: Museu de Prehistòria de València.

Cámara Serrano, J. A. \& Molina González, F. R. (2008). Los Millares. Guía del enclave arqueológico. Andalucía, España: Junta de Andalucía Consejería de Cultura.

Fuentes, F., Mencía, P. \& Sánchez, M. (2010). El Museo de las villas romanas de Almenara-Puras (MVR). Un modelo de gestión sostenible, responsable y comprometida con el Patrimonio Arqueológico. En VII Congreso Internacional Ar\&pa Economía del Patrimonio Cultural, Valladolid Junta de Castilla y León, Consejería de Cultura y Turismo 2010, pp. 179-184. Valladolid, España: Consejería de Cultura y Turismo.

Galve, F. \& Benavente, J.A. (2004). El cabo de Andorra (Teruel): un complejo arqueológico de divulgación de la cultura ibérica del Bajo Aragón. En Congreso Internacional sobre Musealización de Yacimientos Arqueológicos, Ayuntamiento de Zaragoza-IFC. Zaragoza, España: Área de Cultura y Turismo, Servicio de Cultura.

Garcerá, A., Martínez, A. \& Soler, A. (1993). Estudio antropológico de los restos óseos hallados en Requena. En Actas del Il Congreso Nacional de Patología. Valencia, España: Asociación Española de Paleopatología, Universitat de València.

Garcerá, A., Martínez, A., Soler, A. \& Ortiz, J.M. (1993). Estudio odontológico de los restos humanos hallados en la necrópolis de Requena. En Actas del II Congreso Nacional de Patología. Valencia, España: Asociación Española de Paleopatología, Universitat de València.

García Cuetos, M. P. (2012). Humilde condición: el patrimonio cultural y la conservación de su autenticidad. Gijón, España:Trea.

González-Varas, I. (2008). Conservación de bienes culturales: teoría, historia, principios y normas. Madrid, España: Cátedra.

Hernández, F. (2010). Los museos arqueológicos y su museografía. Gijón, España: Trea.

Iglesias J.M. \& Cepeda, J.J. (2004). Julióbriga. Una ciudad romana en el norte de Hispania. Boletín GC: Gestión Cultural y Turismo Arqueológico, 9, 2-19.

Jimeno, A. (2013). Numancia: divulgación y gestión. Estudios del Patrimonio Cultural, 11, 8-20.

López-Menchero, V.M. (2012). Manual para la puesta en valor del patrimonio arqueológico al aire libre. Gijón, España: Trea.

López-Menchero, V. M. (2013). La musealización del patrimonio arqueológico in situ. El caso español en el contexto europeo. Oxford, Inglaterra: International Series.

Martínez, A. (1991). Una inscripción hallada en La Calerilla (Hortunas, Requena). Saguntum: Papeles del Laboratorio de Arqueología de Valencia, 24, 167-172.

Martínez, A. (1995) El monumento funerario de La Calerilla de Hortunas (Requena, Valencia). Archivo Español de Arqueología, 68, 259-281.

Masriera, C. (2007). Anàlisi dels espais de presentació arqueològics de l'edat dels metalls (Tesis doctoral). Barcelona, España: Universitat de Barcelona.

Masriera, C. (2008). Presentación del patrimonio arqueológico: ruinas «versus» reconstrucciones, ¿Qué entiende más el público? En Íber Didáctica de las Ciencias Sociales, Geografía e Historia, 57, 39-51. Barcelona, España: Graó.

Masriera, C. (2009). Las reconstrucciones arqueológicas: problemas y tendencias. Hermes: Revista de Museología, 1, 41-49. 
Moreno, A. \& Haro, M. (2006). El Centro de Interpretación de Los Millares recrea la vida de la prehistoria andaluza. PH Boletín del Instituto Andaluz del Patrimonio Histórico 58, 14-15.

Noguera, F., Guimaraens, G., Lara, S. \& Noguera, M. (2011). Teatros romanos de Hispania: introducción a su estado de conservación y criterios de restauración. Arché, 7, 383-390.

Ramos, M. L. (2003). Tejas romanas procedentes de las termas de San Juan de Maliaño (Cantabria): estudio analítico y experimental. En C.A.E.A.P., 25 años de investigaciones sobre el Patrimonio Cultural de Cantabria (pp. 173-191). Santander, España: Asociación Española de Arqueología Experimental

Ruiz Jiménez, J. (2012). Musealización e impacto cultural en las ciudades actuales de sus vestigios arqueológicos antiguos: un estudio europeo (Tesis doctoral). Universidad Autónoma de Madrid, Madrid, España.

Pou, J., Sanmartí, J. \& Santacana, J. (1995). La Reconstrucció del Poblat Ibèric d'Alorda Park o de les Toixoneres (Calafell, Baix Penedès), Tribuna d'Arqueologia 1993-1994, 51-62. Recuperado de https://tribunadarqueologia.blog.gencat.cat/

Santacana, J. \& Masriera, C. (2012). La arqueología reconstructiva y el factor didáctico. Gijón, España: Trea.

Santos, K., Martínez, A. \& Carrascosa, M. B. (2015). El yacimiento arqueológico de "La Calerilla" de Hortunas (Requena), 25 años después. Oleana 28, 5-26.

Santos, K., Martínez, A. \& Carrascosa, Ma B. (en prensa). Proceso de puesta en valor sostenible en el yacimiento arqueológico de La Calerilla de Hortunas, Requena (Valencia). VII Congreso de Historia Comarcal. Infraestructuras y patrimonio en la meseta de Requena-Utiel, Centro de Estudios Requenenses.

Santos, K., Lorenzo, F., Carrascosa, M. B. \& Martínez, A. (en prensa). I Campaña de Conservación y Restauración en el yacimiento arqueológico de La Calerilla de Hortunas, Requena (Valencia).

\section{Cartas Internacionales}

Carta de Atenas. (1931). IV Conferencia Internacional de Arquitectos y Técnicos de Monumentos Históricos, Atenas 1931.

Carta de Burra. (1979-1982-1988). Carta para la conservación de lugares de valor cultural. Carta del ICOMOS Australia para Sitios de Significación Cultural adoptada en el encuentro del ICOMOS (Consejo Internacional de Monumentos y Sitios) en la histórica ciudad de Burra (Australia).

Carta de Cracovia. (2000). Principios para la conservación y restauración del patrimonio construido. Conferencia Internacional sobre Conservación y "Cracovia 2000" Ciudad de Cracovia (Polonia) 2000.

Carta internacional para la gestión del patrimonio arqueológico. (1990). Carta de Lausana. Preparado por el Comité Internacional para la Gestión de los Recursos Arqueológicos (ICAHM) aprobado por la 9a Asamblea General del ICOMOS Lausana (Suiza) en 1990.

Carta del Restauro. (1932). Elaborada en 1932 por el Consejo Superior de Antigüedades y Bellas Artes de Roma.

Carta del Restauro. (1972). Ministero della Pubblica Istruzione, Roma 1972.

Carta de Venecia. (1964). Carta Internacional sobre la Conservación y la Restauración de los Monumentos y los Sitios. Segundo Congreso de Arquitectos y Técnicos de Monumentos Históricos en Venecia, 25 al 31 de Mayo de 1964.

Ley del 13 de mayo de 1933 sobre defensa, construcción y acrecentamiento del Patrimonio Histórico-Artístico Nacional. Ministerio de Instrucción Pública y Bellas Artes, Gaceta de Madrid, n 145 página 1393, Madrid, España. (Esta Ley no tiene número)

Ley 16/1985, de 25 de junio, del Patrimonio Histórico Español, BOE de 29 de junio de 1985, Madrid, España. 